Volume (4) No. (3) 2021

\title{
Managerial Succession Planning for School Principals: introduction to Organizational Development in the light of Rothwell's Model
}

Hamada Roshdy Abdelaty Abdellah 


\title{
Managerial Succession Planning for School Principals: introduction to Organizational Development in the light of Rothwell's Model
}

Hamada Roshdy Abdelaty Abdellah

Ph.D. Researcher at Department of Comparative Education and Educational Administration, College of Education, Minia University, Egypt. hamada.2742885@t3.moe.edu.eg

Presented in 9th July 2020

Accepted in 1st June 2021

\begin{abstract}
The aim of the current research was to theoretically analyze the Rothwell's model for succession planning and to clarify its sequential steps for the preparation of the alternative leader, as well as to theoretically analyze the job description card (form) for the school principal in the Egyptian Ministry of Education, in order to come up with some suggestions for the preparation of the second-line leadership at school or the alternative leader in a model scientific manner that is proven successful. To achieve the aim of this research, the descriptive research method was adopted in order to describe and clarify the studies related to the two variables of the present research, in addition to attempting to come up with theoretical generalizations that can be used. This research concluded with a proposal to plan the succession of the school principal in light of the Rothwell's model, which consists of seven steps, each step includes a set of executive procedures that take place inside the school and through which succession planning can be achieved for the school principal.
\end{abstract}

Key Words: Alternate Leader, Second-Line of Leadership, Leadership Succession. 


\section{Introduction}

Among the most important successful policies of human resources is planning for everything that goes on inside the institution, that is why nothing happens all of a sudden or by chance. Planning for the succession of those who leave the main leadership positions is one of the most successful of these policies. They are considered as the harvest of the outcomes of organizational learning, as well as one of the aspects of intellectual capital investment at the institution, in addition to taking advantage of the competencies and leadership talents of employees so as to achieve the organizational stability and increase the effectiveness of the institution in achieving its goals.

On the educational level, we find that the position of the school principal is one of the most important administrative jobs in which stability is reflected in the organizational stability of schools, and students' high educational results. This is in agreement with the study of (Tuffaha, 2020) which added that the principal plays a vital role in establishing the school's success and maintaining it through passing on the leadership and technical knowledge and expertise to all teachers and developing them professionally. Robey (2020) pointed out that the school principal performs several multiple tasks that include technical interventions, periodic meetings, continuous advice, participation in formulating goals, and continuous evaluation of all inputs of the educational process at school.

In view of the importance of the role of the school principal, there must be careful planning for the person who will succeed him/her or replace him/her after retirement or in case of any other sudden circumstances. In other words, succession planning must take place, through which many organizational problems can be avoided and more opportunities for the development of school work can be provided. This is confirmed by Yucedag \& Metcalfe (2018) as well as Peters, Reed \& Kingsberry (2018) who stated that succession planning for the school principal achieves leadership sustainability that leads to a strong and stable leadership which is one of the main elements that have a positive impact on the effectiveness of the school and student achievement. As the sudden leadership transition makes the school vulnerable, as well 
as increases the difficulty of maintaining the educational programs and initiatives that are being implemented.

Therefore, planning for the succession of the school principal revolves around the preparation of an alternative from school personnel who have the capabilities, competencies and high talent for leadership when the position of the school principal is vacant for any reason, as well as avoiding the occurrence of any disorder. It is thus a planned and systematic process that involves several important things, including knowledge management, organizational learning, transfer of experience and professional development, continuous assessment, and other processes that achieve the primary goal of succession planning. One of the important things is to refer to experimental global models in managerial succession planning in order to avoid making mistakes, build on them and adapt them to suit the actual reality of schools.

\section{Research problem:}

Reviewing the study of (Schmidt \& Bottoms, 2011), it was found that it indicates how difficult and complex the work of school principals is, and that it goes beyond the limits of the experiences that teachers gain during their careers. This requires the preparation of leaders for the future with a correct succession planning model. This is confirmed by (Russell \& Sabina, 2014) who added that succession planning for school principals which is based on experimental models achieves high results in uncovering the most prominent highly skilled candidates who can succeed their principals. In agreement with that, the study of (Peters, Reed \& Kingsberry, 2018) argued that planning for the succession of the school principal may be applied incorrectly if it is done in a random, non-standard manner that is not based on the primary goal of succession planning, which is the sustainability of leadership and stability within the school. In addition, it is sometimes applied to be a quick solution to the shortage problem or to other demands for reform.

Based on the Rothwell's model, Zepeda, Bengtson and Pary (2012) admitted that succession must be properly planned in accordance with studied models in order to ensure sustainability as well as effectiveness. Armugam et. al (2019) is in agreement 
with this study in acknowledging the importance of the Rothwell's model and its use in succession planning for school principals. Besides, Nabawi (2016) pointed out the importance of the Rothwell's model as one of the modern models in management thought to succession planning and preparation of the second-line of educational leaders.

The previous review clearly shows the importance of planning for administrative succession due to the stability that it provides in working inside schools, especially if it takes place in light of experimental models prepared in accordance with studied scientific steps. That is like what was indicated previously, that is, the Rothwell model for planning succession in seven sequential applicable steps. On the national level, there is an urgent need for such successful models, as the researcher noted, through his work in the field of education, a lack of interest in the process of planning for succession of school principals, in addition to the superficiality as well as routine of the courses of professional development which are provided in this aspect. Consequently, this negatively affects the educational process inside schools.

Ghoneim \& Muhammad (2016) affirmed that the succession planning of leadership in the Egyptian Ministry of Education is subject to ineffective foundations and standards, in addition to the little commitment of the higher board of management to the administrative leadership succession planning programs. Besides, there is no objective system for performance assessment through which those with high administrative and leadership capabilities can be identified, as well as there is an urgent need to activate the succession planning process at the level of the Egyptian Ministry of Education as a whole in all its schools.

Therefore, it is clear that the process of succession planning is not activated at the national level in the pre-university education schools, in spite of its great importance in bringing about organizational development and facing developments and changes that take place in the educational system, in addition to identifying the leadership capabilities and inherent readiness of workers at schools. Therefore, many new school principals fail to perform their roles in varying degrees, affecting in one way or another 
the success and effectiveness of the educational process within the school in achieving its goals. Accordingly, the search for successful applicable models in succession planning for school principals is extremely important. The Rothwell's model is considered as one of the most prominent of these models and comes on the top in many studies that dealt with the topic of succession planning. Hence, the main research question can be formulated as follows:

- How can succession planning of pre-university school principals be planned in light of Rothwell's Seven-Step Model?

This main question branches out into the following sub-questions:

1- What is the nature of the ideal role played by school principals in the Egyptian Ministry of Education?

2- What is the intellectual framework of Rothwell's Seven-Step Model for succession planning?

3- What is proposed to benefit from Rothwell's Seven-Step Model in planning the succession of school principals in the Egyptian Ministry of Education?

\section{Research aims}

The aim of the current research was to identify the nature of the ideal role that is played by school principals in the Egyptian Ministry of Education, as well as to identify the features of the intellectual framework of Rothwell's Seven-Step Model for succession planning, in order to reach intellectual approaches that help in providing a proposed vision to benefit from Rothwell's Seven-Step Model in planning the succession of the pre-university schools' principals in the Egyptian Ministry of Education.

\section{Research significance}

The significance of the present research stems from the importance of the role played by school principals in the educational process, as well as the research's attempt to reach theoretical generalizations that are useful in preparing the alternative leader or the second-line of leadership through theoretical analysis of the steps of the Rothwell's model. In addition, this research attempted to find procedural proposals that can take 
place within schools at the decentralized level to plan the succession of school principals in a studied scientific manner, that contributes to supporting the educational process.

\section{Research delimitations}

Being a theoretical research, its objective was limited to describing the nature of the ideal role of the principal as mentioned in the job description card (form) of the Egyptian Ministry of Education, with a presentation of the Rothwell's model and its sequential steps for succession planning.

\section{Definitions terms}

\section{1- Succession planning:}

Bottomley (2018) defines it as a long-term strategic planning to enhance stability within the institution, including identifying employees with leadership capabilities and competencies as well as working on developing them in order to prepare future leadership cadres for ensuring the continuity of leadership. According to this study and its specialization, succession planning can be operationally defined as a systematic process that aims to search for the best teachers who have readiness and leadership abilities, and who meet the legal terms and conditions to occupy the position of the school principal, and to assist and develop them professionally in this aspect so as to become candidates for future leadership to ensure the stability of the educational process, as well as to ensure that there are no organizational problems that might be caused by the sudden vacancy of the position of school principal.

\section{2-School principal:}

Issa (2018) defines a school principal as the person who is responsible for all matters related to the technical and administrative aspects of the school, such as planning, organizing, evaluation, communication, community participation, financial aspects, technical supervision, and follow-up of the school curricula, so as to implement the educational policy. It can be operationally defined as the person who leads the educational process inside the school, and ensures the achievement of the goals of the educational stage in which he/she works. This involves practicing the main operations 
of the administration, namely planning, coordination, implementation, and evaluation as well as follow-up of all teachers of the school, students, assistant workers, curricula and study activities, in addition to the relationship of the school with society, and related sub-actions.

\section{Research Methodology}

The current research adopted, in achieving its aims, the descriptive method due to its relationship to the nature of the research. Moreover, the descriptive method increases the understanding of the educational phenomenon, helps in reaching facts about the current conditions (Rothwell, 2015), and also develops important relationships between the current phenomena and data interpretation so as to identify the steps of the Rothwell's model and to describe them accurately, with an explanation of the nature of the principal and his/her duties, with the purpose of reaching a proposal that may enable to plan the succession of the school principal in a correct way.

\section{Related studies}

Previous studies are useful in forming a clear vision on the topic of the current research through what it provides of accurate information that contributes to crystallizing the research problem and its questions. The researcher has reviewed a set of Arab and foreign studies that dealt with the general idea of the research, that is, succession planning in the educational field. These studies will be presented in chronological order from the oldest to newest. The first to begin with is the study of (Rothwell, 2015) in which he presented his vision on planning for leadership succession as proactive steps planning for the future leadership needs of the institution from current workers who have leadership skills and talent. He also indicated that there is a deficiency in the job description regarding daily dealing with colleagues, superiors and subordinates, and that all institutions should review the job descriptions to facilitate succession planning. Furthermore, in his study, Rothwell also identified his model for implementing succession planning in a number of stages. 
In addition, Zepeda, Bengtson \& Pary (2012) conducted a study aimed to review the succession planning of school principals in four schools in Georgia. The descriptive method was adopted, and semi-structured interviews were used to collect data. Findings of the study indicated the importance of succession planning for school principals as it achieves leadership sustainability and effectiveness within the school. This is reflected in the performance of the school as a whole and student achievement in particular. This study has given importance to the use of Rothwell's model for succession planning, as well as building collaborative partnerships with universities and other external professional development organizations.

The study of (Nabawy, 2016) pointed out the lack of Arab studies regarding the issue of succession planning and that the studies which dealt with this topic discussed it and inadequately and superficially. This study presented scenarios for preparing the second-line of educational leaders in the light of the modern administrative thought, based on several models for succession planning. Rothwell's model, Karan model, and the talent management model come on the top of these models. Findings of this study concluded that the succession planning practices that take place in the Egyptian educational institutions are superficial, traditional and ineffective. In addition, based on the Rothwell's model, the study emphasized the effectiveness of succession planning.

Among the local Arab studies also is the study of (Ghoneim \& Muhammad, 2016) which aimed to investigate the possibility of planning for leadership succession in the Egyptian Ministry of Education as well as to identify the most prominent international models and practices in that respect. To this aim, the descriptive method was adopted and the questionnaire was used to collect data. Findings pointed out that Rothwell's model is one of the most prominent models used in succession planning, and revealed the existence of some organizational, material and human obstacles that stand in the way of succession planning process. It was recommended that the Ministry of Education should adopt an objective model that enables the discovery of talented and high-performing individuals to facilitate succession planning. 
Brayant, Escalante and Selva (2017) conducted a study aimed to reveal the practices that principals do so as to plan succession, to build the second-line of leadership, as well as to identify the factors that help or hinder this process. To this aim, this study adopted the case study method and used the interview, observation and analysis of documents to obtain data. It was conducted in one of the educational/ school districts in California, and its sample consisted of 3 school principals and some teachers in the district. Findings of this study indicated that the school principal is able to provide professional development for teachers who are candidates to leadership in the future without affecting their commitment to students, by providing real administrative opportunities for them.

Besides, the study of (Parfitt, 2017) aimed to enrich the succession plans for school principals by examining the perceptions of current principals and candidates for leadership, as well as by providing good opportunities for guidance and professional development in their light. This study was conducted on a sample of 12 school principals and candidates for leadership. It adopted the descriptive method and questionnaire to collect data. Findings of the theoretical analysis of the study indicated the characteristics of succession planning as defined by Rothwell, and also pointed out that succession planning includes individual professional development plans for leadership candidates to meet the future administrative needs of schools. In addition, formal and informal guidance are important for candidates with the necessity for rewarding them, continuous analysis of school conditions and using the results of the analysis to enhance succession plans and amend them to achieve the desired outcome, with the necessity of respect for the organizational culture prevailing in the school.

Fusarelli, B., Fusarelli, L., and Riddick (2018) conducted a study aimed to search in the best practices for planning the succession of school principals through the use of human capital theory. This study was conducted using the descriptive method and the study sample represented in rural schools in the state of North Carolina. Findings indicated the need for cooperation between universities and civil organizations with schools in developing long-term strategic plans to plan the 
succession of school principals after reaching retirement age, emphasizing the importance of the participation of current school principals in implementing and managing these plans.

Additionally, Cieminski (2018) carried out a study with the purpose of examining and reviewing succession planning practices for school principals in five educational districts in the Colorado City. This study adopted the descriptive research method and used semi-structured interviews with some principals and administrators so as to collect data. Findings of the study revealed that the current school principals have to assist teachers who are candidates for leadership through succession plans by guiding and providing professional development for them. The study recommended the need to formalize succession plans so that they do not change with the change of senior management outside the school; as succession planning provides more effective leaders for schools in the future.

In a study conducted by (Sabina, 2018) aimed to identify the challenges that face succession planning of the school principal from inside and outside the school with an explanation of the benefits and constraints of that. This study was carried out in five schools in Central Florida using the descriptive analytical method as well as the interview for the purpose of data collection. Findings of the study revealed the existence of some obstacles to nominating a principal from outside the school, the most prominent of which is the occurrence of general dissatisfaction among the workers. On the other hand, among its advantages is that the external candidate brings new views, culture as well as additional relationships to the school. It was recommended in this study that the external candidate is required to respect the succession, culture and the organizational climate of the school.

Furthermore, Hayes (2020) carried out a study with the purpose of revealing the perceptions of the principals who are candidate for school leadership, in a professional development program within the succession planning program presented by the leadership academy under the auspices of the University of Texas. The case study method was adopted and the semi-structured interview was used with the purpose of 
collecting data. The perceptions of 26 principals, who are candidates for leadership in one educational/school district in the state of Texas, were revealed. Findings of the study indicated that the participants are more confident and effective after the professional development program, as well as are more ready to implement the leadership succession. Findings also pointed out the importance of the partnership between the universities and schools in planning the succession of school principals.

\section{Commentary on the previous studies:}

The current research is in line with the above-mentioned studies in addressing the issue of providing an alternative leader for school principal or building the secondline of school leadership in a planned systematic manner, in addition to the scarcity of this at the local level in the Egyptian Ministry of Education as indicated by the study (Ghoneim \& Mohamed, 2016) and (Nabawi, 2016), as they pointed out the scarcity of local studies that dealt with this topic and the superficiality of investigation of studies. They also revealed the actual reality as they showed the existence of some organizational obstacles in schools that must be overcome, and that there is an urgent need for succession planning to ensure organizational stability in schools and the development of educational reform plans. In general, local studies helped the current research to a high degree in crystallizing the research problem and its questions, in addition to presenting some proposals.

The current research also benefited from previous studies in learning about the Rothwell's model, as well as in identifying its methodological steps, in addition to how to make procedural projections within the educational context in schools. As most of these studies clarified the application of succession planning in schools, and recommended the importance of the Rothwell's model in this area, such as the study of (Ghoneim \& Muhammad, 2016), (Nabawi, 2016), (Rothwell, 2010) (Zepeda, Bengtson $\&$ Pary, 2012) and (Parfitt, 2017). Some previous studies also emphasized the importance and effectiveness of participation and partnerships between universities and schools in carrying out succession planning, such as the studies of (Hayes, 2020) as well as (Fusarelli, Fusarelli \& Riddick, 2018). 
To add, the current research benefited from the previous studies in forming a vision about the steps of the study, and defining the appropriate research method. They also provided many theoretical information and scientific references conducted in succession planning at the educational level that helped in building the theoretical framework for the current research, and also contributed to the crystallization of some proposals for succession planning based on Rothwell's model in a way appropriate to the local reality.

\section{Theoretical framework:}

First: the nature of the ideal role of the principal as stated in the job description cards/forms.

One of the most important roles in the educational system is the role of the principal. Principal is considered as the role model for all school employees as well as students. He/she must be on the level of that responsibility and bear its consequences, and is responsible for many of the tasks and duties that he/she must do so as to achieve the educational goals for the stage of education in which he/she works. He/she implements the general policy of the Egyptian Ministry of Education within the school. Therefore, the Ministry prepared cards/forms to describe the duties of the school principal, which were developed many times to be in line with the change that occurs in the educational system, up to the job description cards issued in 2016, as they stipulated some tasks that define the ideal role of the school principal and the tasks assigned to him/her.

The Ministerial Resolution for the job description briefly stated that the principal of the school has to be responsible for leadership and institutional supervision through the application of accountability, teamwork, communication support, use of technology in education and management, supervision of security and safety, newly created units, examination works, as well as evaluation and follow-up. He/she is also responsible for supervising the educational process and ensuring that modern educational strategies and methods are used. In addition, the principal is also responsible for ensuring quality 
standards and accreditation as well as assisting in qualifying the school for educational accreditation.

Continuing professional development is also among his/her responsibilities through the Training and Quality Unit, in addition to providing direct advice and continuous guidance to workers, and finally, the community participation and communication with the community through cooperation with the parents' council. The Ministerial Resolution also stipulated the conditions for occupying the position of school principal, that is, the applicant holds a high educational qualification as well as the grade of senior teacher. The applicant must also meet the professional development programs approved by the professional academy for teachers and obtain a certificate of practicing the profession. In addition, the appointment is for a period of two years and renewed for another period (The Egyptian Ministry of Education, 2016).

By reviewing the ministerial resolution that is referred to previously, we find that the tasks of the principal are limited to four main axes, mainly leadership and institutional supervision, supervising the educational process, professional development, and community participation. Moreover, after examining and reviewing the sub-operations of these main axes, it was noted that they are free from any reference to the planned succession. In other words, the statement "the principal who is on the job assigns an alternative leader that replaces him/her after the end of his/her specific period to occupy the job in a legal and planned manner" does not exist, and this is considered a deficiency in the job description of the school principal, such as what was referred to by Rothwell (2010).

Although there are specific terms and conditions for filling the job and limiting it with time periods in the range of two years renewed in accordance with the vision of the higher administrative levels. This indicates a continuous replacement and renewal of the position of the school principal. Consequently, there is an urgent need for the alternative leader whose succession is planned, so that the organizational stability is maintained within the school and that no problems arise from the sudden vacancy of the position of the principal of the school, the most prominent of which may be the 
organizational struggle. Such organizational struggle results in tension and disorder in the organizational climate of the school, that negatively affects the progress of the educational process.

\section{Second: the intellectual framework of Rothwell's Seven-Step model for succession planning.}

Zepeda, Bengtson and Pary (2012) stressed the importance of transferring succession planning models from business models to the educational field, with the necessity for continuing research on this important educational issue (26). In the same context, Bengtson, Zepeda \& Pary (2013) also stressed the importance of finding procedural models to clarify the ways to support school systems in their attempt to implement management succession practices for school principals, so that they can be able to effectively perform their educational function. William Rothwell is considered one of the most prominent theorists in the topic of succession planning. His model for succession planning, known as the Seven-Pointed Star Model, has gained wide fame in the business environment as well as educational field. He built this model from 2001 to 2010 , and during this period the model went through many modifications until it appeared in its current form.

Rothwell views that succession planning is a deliberate and systematic effort by the institution to ensure the continuity of filling its main leadership positions, to preserve its intellectual / knowledge capital, as well as to develop and prepare it to keep pace with future requirements, and to encourage the progress and promotion of the institution's employees (Villella, 2016). From Rothwell's point of view, it is clear that succession planning is one of the pillars of the institution's organizational development as it is a long-term, intentional planning aims to develop the organization in an important aspect, that is, leadership, in addition to achieving leadership sustainability to ensure organizational stability.

Moreover, maintaining intellectual capital is one of the recent trends to plan human resources and identifying career paths. It seems that succession planning, in Rothwell's model, is no longer a narrow concept as some writings indicated to it as an 
heir preparation, but he skipped and went beyond that and provided the principle of equal opportunities among all workers to occupy leadership positions according to their potential and capabilities. It is evident that there are successive and procedural professional development programs covering several areas of leadership. Accordingly, Rothwell presented the Seven-Pointed Star Model for planning management succession in seven sequential steps, which are briefly as follows:

\section{1- Make the commitment:}

This step includes the recognition and commitment of the higher board of management and organization's decision makers to the management system and implementation of succession planning by linking it with the organization's strategy, building specific programs based on foreseeing future work requirements through an analysis of the current workforce. A written procedural action plan is prepared to guide the program at start-up and communicating it to inform the related parties, with explanation of plans, clarification of the expected results, presentation of facts, participation of individual and preparation for the application (Rothwell, 2015).

It is clear that this step indicates the necessity for the succession plans to be fixed and adhered to by the top management and decision makers of the organization even if they were changed, but this is conditional on building succession plans in a clear and objective manner based on the existing facts in the actual reality of the human resources against the future needs of leaders, provided that all individuals are allowed to participate and review what the plan contains as well as take their opinions into consideration. Besides, this plan is to be formulated in the form of clear procedures with a degree of flexibility so as not to contradict the prevailing organizational culture.

\section{2- Assess present work requirements:}

In this step, the organization's decision-makers determine the main leadership positions in the organization and the competencies required to these positions. Through this step, preparations can be made to prepare and qualify individuals with job requirements so that they can be ready to advance in achieving the requirements of leadership positions (Kim, 2017). This step demonstrates the necessity for identifying 
the leadership positions required in each section of the organization with an indication of the role that each position plays, and clarifying the competencies and skills that are available in applicant who will occupy this role in order for individuals to be able to prepare for them and acquire and learn them through the professional development programs and special directives provided by those in charge of succession plans.

\section{3-Appraise individual performance:}

In this step, the extent of each individual's mastery of his/her work is evaluated, as succession planning programs are based on the principle that employees master the performance of their current jobs and then deserve to be promoted to higher positions in the future. The third step of the model is one of the important steps in managing leadership talent, and facilitates the process of setting expectations for each individual for a specific leadership role based on their competence and skill. One of the most prominent procedures that can be used to assess individual performance is empirical situations and actual observations of practices and behaviors by decision makers (Kim, et. al, 2014). It is noted that this procedural step of the model aims to form an integrated, individual image for each individual in the organization by evaluating performance in several different ways. This image provides information about the individual's mastery of the work assigned to him at the present time and the extent of his/her aspiration to the future, his skills, ways of thinking and treatment of the course of daily matters, and his/her commitment and organizational loyalty.

\section{4- Assess future work requirements:}

This step includes looking to the future to answer some questions, such as how will the organization be in the future?, what change can happen?, how are workers and leaders prepared for it?, what skills are required for leadership work?, what are the key leadership positions in the future and what are their requirements? (Rothwell, 2013). It is clear from this step that those responsible for succession planning at the organization predict and develop scenarios for the future based on organizational analysis. These scenarios determine the leadership positions required in the future, with the identification of the competencies and skills necessary for fulfilling them, and then 
include them in the professional development plans of the candidates for the leadership succession to train in and master them.

\section{5- Assess future people requirements:}

The individual capabilities of workers at the present time are compared to the most demanding and highest-level work in the future (Rothwell, 2011). In this step, a prediction process occurs regarding what will become the capabilities of individuals in the future, what are their job competencies and talents and how they correspond to the requirements of future work. This step is useful for determining the suitability of the individual for future tasks; however, it is not used to assess the current performance of the individual as the assessment tools differ. As in this step, the aim is the future.

\section{6- Close the developmental gap:}

Continuous professional development programs are carried out within the organization based on what has been revealed from the current performance and future job requirements, in addition to attempting to bridge the gaps between them with these programs to prepare future leaders (Rothwell, 2015). In other words, in light of the results of the previous steps, such as work requirements assessment and the assessment of individuals' performance, their competencies and their current and future talents, professional development programs are built to overcome the deficiency and fill the gap between what the current performance is and what it should be in the future.

\section{7-Evaluate the succession planning program:}

The succession planning program must undergo continuous evaluation in each step in order to identify the extent to which the goals have been achieved, to make the necessary improvements, as well as to maintain commitment according to a clear methodology (Kim, et. al, 2014). This process comes to ensure continuous development and improvement, and the results of the evaluations should be taken into consideration by the organization's decision makers and those who are in charge of the succession planning management. In addition, there are no specific scales, but rather various scales are adopted depending on the nature of each organization and the organizational culture prevailing in it. 


\section{Third: A proposal to benefit from Rothwell's Seven-Step Model in planning the succession of school principals in the Egyptian Ministry of Education.}

Based on the previous studies, and after presenting the job description of the school principal, identifying the tasks of the ideal role he/she plays as mentioned in the regulations and decrees of the Ministry of Education, as well as presenting the seven steps of the Rothwell's model for succession planning, the researcher came up with a proposal to plan the succession of school principals in seven sequential steps, which are presented as follows:

\section{1- Making the commitment:}

In this step, the Ministry of Education is committed to issuing the necessary administrative and financial regulations for carrying out the succession plans for the principal at the decentralized level, and the higher departments for education outside the school, represented by educational directorates and administrations adhere to the principle of decentralization of school administration, in addition to ensuring that the school is the unit in which development and change occur, as it is the field of interaction between the inputs of the educational process, and that the development plans may vary from school to another. As a result, schools are allowed to rely on themselves in building, implementing and evaluating the plans for the administrative succession for their principal in a manner appropriate for their circumstances and the nature of their organizational culture, as well as the level of human resources available within them, which ensures organizational stability. This is in addition to the commitment of the educational administrations to preparing schools to provide the requirements for succession planning for their principals by activating the ministerial decrees related to adherence to the conditions for appointing the school principal and preventing internal assignment from educational administrations, such as the ministerial decree regrading job description mentioned previously, and the administrative orders issued by the ministry, such as the administrative order No. 1-2020 (The Egyptian Ministry of Education, 2020). It is necessary to start by the national standards and strategic plan of 
Egyptian education 2014/2030, as a basic reference for succession planning and school development, and to implement the principle of educational reform based on the school.

The school develops a specific committee to manage the succession planning of the school principal, and it is suggested that the committee consists of the school principal and be responsible for it, the membership of the school's human resources manager to provide a valid and constantly updated database, and the membership of the school's quality and training unit manager for continuous professional development procedures and conducting assessments. The committee consists also of the membership of representatives of teachers, as pursuant to the principle of transparency in the work of the committee as well as for participation in decision-making and formulating the vision and mission of the committee that should emerge from the school's vision and mission and be included in the school's strategic plan, in addition to the membership of a representative of the Parents and Trustees Council to ensure support through community participation. This committee prepares to establish the culture of succession planning in the school by spreading awareness among teachers and using appropriate organizational analysis and diagnostic tools in formulating and implementing the succession plan. It is also responsible for saving plans officially approved.

The school administration invites teachers to hold a general meeting and informs them about succession planning and the quality committee developed to manage it, and this is documented in official records for the school board, knowing that these records have a legal period of five years to ensure commitment when a sudden change may occur from within or out of school under any circumstances. The Special Committee for the Department of Succession Planning before employees and administrative bodies outside the school is committed to objectivity and transparency in the performance of its tasks, and the school administration is committed to providing a budget for the activities of the succession planning committee and its activities. The Education administration is committed to providing a degree of accountability for succession 
planning work within schools through the Quality Measurement Department and the Training Department to establish the concept of commitment and seriousness.

\section{2- Assessing present work requirements:}

In this step, the job description cards/forms of the principal of the school as defined by the Ministry of Education are referred to and emptied into major axes as previously explained, which is the responsibility of leadership and institutional supervision. This step also includes the technical supervision on the educational process, professional development of all workers, and community participation. The skills and competencies required for each mission are identified in a simplified procedural form that is formulated in the form of professional development programs that are included in the annual plan of the Training and Quality Unit to train candidates for succession in.

\section{3- Assessing individual performance:}

The current performance of teachers who wish to join the planned succession program is assessed individually in some aspects, such as the extent of regularity and discipline in work, respect for it, use of the right to leave, subject to disciplinary sanctions, evaluation of his/her behaviors with superiors, colleagues, students, and parents, the degree of his/her participation in improving school work performance, the extent of his participation in the daily supervision work and specific committees, his/her proficiency in preparing lessons and delivering information to students and achieving high educational results, his ability to manage class, leadership and guiding, degrees obtained and training courses, and the extent of knowledge in his/her field of specialization, and his/her commitment to the ethics of the education profession and its national standards. Assessment scores are calculated according to what the committee of school succession planning management sees. Based on the results of this assessment, an arrangement is produced for the successive candidates indicating the degree of readiness and priority for each of them, and this contributes to determining the depth of the professional development programs and the guidance provided by the unit of training and quality at school. 


\section{4- Assessing future work requirements:}

In this step, the tasks of the principal of the school will be predicted in the future and what it will be like. Most of the changes that occur refer in one way or another to the trend towards information and communication technology and its integration into administrative processes, as well as the teaching and learning process. Therefore, several scenarios that include a list of professional development programs are formulated to serve these aspects. These scenarios are included in the training and quality unit plans to train candidates for succession in order to be familiar with the duties of the school principal in the future.

\section{5- Assessing future individuals' requirements:}

Some individual capabilities and skills that have implications for the professional future of the candidates are considered, such as the accomplishments or works that exceed the work performance rates with the required quality and appropriate timing, the tangible effort in proposing practical solutions to problems that hinder the future workflow, and the superior capabilities in developing work systems within the school, scientific and creative thinking, permanent review of developments in the field of specialization, aspiration to be familiar with information and communication technology in school administration, and teaching and learning in the classroom, in addition to a continuous aspiration to self-professional development and e-learning. The assessment process in this step is useful for identifying teachers' job competencies and talents as well as their compatibility with future work requirements, and working to develop them through training programs in the school's training and quality unit.

\section{6- Closing the developmental gap:}

Performance gaps are the product of comparing current performance with future capabilities, as well as current and future work requirements. This takes the form of professional development training needs to meet the responsibilities of candidates for future leadership succession. This is formulated in the form of training programs that are included in annual and five-year plans to be implemented according to a timetable that is adhered to by the training and quality unit, taking into account the provision of 
real experimental administrative opportunities for the candidates by the current school principal, in a manner that does not conflict with their job commitment to students and the school schedule. Programs of professional development are supervised by the school succession planning management committee.

\section{7- Evaluating the succession planning program:}

The evaluation process should be continuous and comprehensive for each step in the program, in order to ensure continuous improvement of the weaknesses that may appear, and to maintain seriousness, with a primary focus on evaluating the professional development programs presented to the candidates, monitoring indicators of success periodically, identifying the levels of progress of the candidates, and taking into account diversification in the evaluation tools to accurately reveal the reality of the program's progress. This step can be done by several parties, including the educational administration's external follow-up in conjunction with the school succession planning management committee and the training and quality unit.

\section{Recommendations:}

- Adherence to the sequence of steps in the succession planning model when implemented.

- The necessity for higher administrative levels to adopt succession plans for school principals and include them in their strategic and operational plans.

- The necessity for the higher administrative levels outside the school to adhere to the conditions for appointing the school principal and prohibiting assignment.

- Providing some financial resources for the school administration to implement the succession plan.

- Diversification of the evaluation tools used in the succession plan stages in a way suitable to each stage and according to capabilities.

- Local studies continue to conduct research on the succession planning process to achieve further development. 


\section{Future studies:}

- The role of the school principal in planning for administrative succession in light of the principle of school-centered reform.

- A proposed vision for some of the criteria for second-line leaders in the Egyptian Ministry of Education schools.

- Contemporary trends to prepare the school principal's alternative leader.

- Professional development as an approach to the preparation of second-line of school leaders. 


\section{References}

- $\quad$ Armugam, B., Arshad, M., Ismail, I., \& Hamzah, S. (2019). Investigating the Link between Transformational Leadership Style on Succession Planning Program in National Secondary Schools in Seremban District. Malaysia. Development, 8(4), 201-241. Retrieved 28/12/2019 from www.hrmars.com/insight.com

- $\quad$ Bengtson, E., Zepeda, S., \& Parylo, O. (2013). School systems' practices of controlling socialization during principal succession, Looking through the lens of an organizational socialization theory. Education Management Administration \& Leadership, 41(2), 143-164. Retrieved 14/1/2020 from Www.journals.sagepub.com/

- $\quad$ Bottomley, K. (2018). Developing Sustainable Leadership Through Succession Planning. Succession Planning: Promoting Organizational Sustainability. P. A. Gordon and J. A. Overbey. Cham, Springer International Publishing: 110.

- $\quad$ Bryant, J., Escalante, K., \& Selva, A. (2017). Promising Practices: Building the Next Generation of School Leaders. Journal of School Administration Research and Development, 2(1), 32-41. Retrieved 29/12/2019 from Www.eric.ed.gov.com

- $\quad$ Cieminski, A. (2018). Practices That Support Leadership Succession and Principal Retention. Education Leadership Review, 19(1), 21-41. Retrieved 5/1/2020 from www.eric.ed.gov.com

- $\quad$ Essa, A. (2018). Modern educational and pedagogical management. Jordon, Ibn al-Nafis Publishing and Distribution House.

- $\quad$ Fusarelli, B., Fusarelli, L., \& Riddick, F. (2018). Planning for the future: Leadership development and succession planning in education. Journal of Research on Leadership Education, 13(3), 286-313. Retrieved 7/1/2020 from www.journals.sagepub.com/ 
- $\quad$ Ghoneim, S., Muhammad, J. (2016): Planning for Leadership Succession in The Egyptian Ministry of Education, Cairo, National Center for Educational Research and Development.

- $\quad$ Hayes, S. \& Burkett, J. (2020). Almost a Principal: Coaching and Training Assistant Principals for the Next Level of Leadership. Journal of School Leadership, 1052684620912673. Retrieved 12/1/2020 from www.journals.sagepub.com/

- $\quad$ Kim, Y. (2017). Succession Planning and Management in Nonprofit Organizations. In the Nonprofit Human Resource Management Handbook (pp. 101-121). Routledge.

- $\quad$ Kim, Y., Williams, R., Rothwell, W., \& Penaloza, P. (2014). A strategic model for technical talent management: A model based on a qualitative case study. Performance improvement quarterly, 26(4), 93-121. Retrieved 22/1/2020 from www.onlinelibrary.wiley.com

- $\quad$ Nabawy, A. (2016). Scenarios for The Preparation of The Second Grade of Educational Leaders in the Light of Trends of Modern Management Thought. Journal of Research in Higher Education, the Faculty of Education, Ain Shams University,32,57-160.

- $\quad$ Parfitt, C. (2017). Creating a Succession-Planning Instrument for Educational Leadership. Education Leadership Review, 18(1), 21-36. Retrieved 3/1/2020 from wWw.eric.ed.gov.com

- $\quad$ Peters-Hawkins, A. L., Reed, L. C., \& Kings berry, F. (2018). Dynamic leadership succession: Strengthening urban principal succession planning. Urban Education, 53(1), 26-54. Retrieved 22/12/2019 from www.journals.sagepub.com

- $\quad$ Peters-Hawkins, A., Reed, L., \& Kingsberry, F. (2018). Dynamic Leadership Succession: Strengthening Urban Principal Succession Planning. Urban Education, 53(1), 26-54. Retrieved 25/4/2020 from www.journals.sagepub.com 
- $\quad$ Robey, P. (2020). The Journey from External Control to Lead Management and Quality Education: An Interview with Robert G. Hoglund. International. Journal of Choice Theory \& Reality Therapy, 39(2), 29-38. Retrieved 21/4/2020 from www.ebscohost.com

- $\quad$ Rothwell, W. (2015). Effective succession planning: Ensuring leadership continuity and building talent from within, 5th Edition, New York, Amacom.

- Rothwell, W. (2011). Replacement planning: A starting point for succession planning and talent management. International Journal of Training and Development, 15(1), 87-99. Retrieved 24/1/2020 from www.wiley.com

- $\quad$ Rothwell, W. (2013). Performance consulting, applying performance improvement in human resource development. John Wiley \& Sons.

- $\quad$ Russell, J. \& Sabina, L. (2014). Planning for principal succession: A conceptual framework for research and practice. Journal of School Leadership, 24(4), 599-639. Retrieved 13/12/2019 from: Www.journals.sagepub.com

- $\quad$ Sabina, L., \& Colwell, C. (2018). Challenges of Principal Succession: Examining the Challenges of Hiring Internal vs. External Candidates. Athens Journal of Education, 5(4), 375-395. Retrieved 2/1/2020 from www.eric.ed.gov.com

- $\quad$ Schmidt-Davis, J., \& Bottoms, G. (2011). Who's Next? Let's Stop Gambling on School Performance and Plan for Principal Succession. Southern Regional Education Board (SREB). Retrieved 2/2/2020 from www.sreb.org/

- The Egyptian Ministry of Education (2016). Ministerial Resolution No. 164, dated (31 May 2016) on the description cards of members of the Education Authority.

- The Egyptian Ministry of Education (2020). Administrative Order No. (1), By prohibiting the assignment of directors internally, the appointment shall be on the Staff Law No. 155 of 2007. 
- Tuffaha, M. (2020). The influence of professional development program on the leadership style of school principals (line managers) in Abu Dhabi governmental schools. International Journal of Psychosocial Rehabilitation, 24(4), 650-660. Retrieved 22/4/2020 from www.ebscohost.com

- Villella, J. (2016). Leadership and Succession Planning, Challenges and Strategies in Developing the Future Workforce. Berkeley, California, Mac Center at University California, Berkeley.

- $\quad$ Yucedag-Ozcan, A., Metcalfe, S. (2018): Case Studies in Succession Planning for K12 Districts. Gordon P., Overbey J. (eds) Succession Planning. Palgrave Macmillan, Cham. 187-198.

- Zepeda, S., Bentsen, E., \& Parylo, O. (2012). Examining the planning and management of principal succession. Journal of Educational Administration. Retrieved 25/12/2019 from wWw.emerald.com/insight.com 